\title{
openheart Exercise-related sudden cardiac arrest in London: incidence, survival and bystander response
}

\author{
Melanie J Edwards, Rachael T Fothergill
}

To cite: Edwards MJ, Fothergill RT. Exercise-related sudden cardiac arrest in London: incidence, survival and bystander response. Open Heart 2015;2:e00281. doi:10.1136/openhrt-2015000281

Received 15 April 2015 Revised 26 July 2015 Accepted 27 August 2015

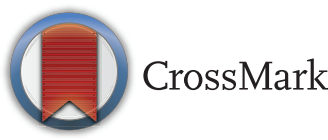

Clinical Audit \& Research Unit, London Ambulance Service NHS Trust, London, UK

Correspondence to Dr Melanie J Edwards; melanie.edwards@rocketmail. com

\section{ABSTRACT}

Objective: The study aimed to (1) establish the incidence of exercise-related sudden cardiac arrest (SCA) in London, (2) investigate survival from exerciserelated SCA and (3) examine factors related to survival. Method: This retrospective observational study examined 2 years' data from the London Ambulance Service (LAS) cardiac arrest registry for patients in whom resuscitation was attempted following an out-ofhospital cardiac arrest (OHCA), a cardiac cause was presumed and the arrest occurred during or within $1 \mathrm{~h}$ of exercise.

Results: The incidence of exercise-related SCA in London was estimated to be 0.6 per 100000 personyears which equated to $0.5 \%$ of all $\mathrm{OHCA}$, and $1.5 \%$ of all OHCA with presumed cardiac aetiology and resuscitation attempted. The majority of cases were male and the incidence increased from age 40 years. Just under one-third of patients survived to hospital discharge. Survival in the Utstein comparator group (cases with presumed cardiac aetiology, resuscitation attempted, bystander witnessed and a presenting cardiac rhythm of ventricular fibrillation or tachycardia) was higher at $42 \%$. Survival was significantly associated with initial cardiac rhythm $\left(\chi^{2}=17.5, \mathrm{df}=2\right.$, $p<0.001$ ) and bystander defibrillation (Fisher's exact test, $p<0.05$ ).

Conclusions: Incidence of exercise-related SCA in the general population in London is rare. Survival following exercise-related SCA was considerably higher than survival for all OHCA with presumed cardiac aetiology and resuscitation attempted attended by the LAS during the same period. The major limitation of the study is the likely under identification of cases of exercise-related SCA.

\section{INTRODUCTION}

There has been heightened public and media interest in exercise-related sudden cardiac arrest (SCA) following the successful resuscitation of a UK premier league footballer and the death of a young female runner at the London Marathon. Research in this field tends to focus on sudden cardiac death (SCD) rather than SCA, presumably because of the low survival rate-11-16\%-

\section{KEY QUESTIONS}

What is already known about this subject?

- Recent studies conducted in mainland Europe suggest the incidence of exercise-related sudden cardiac arrest (SCA) among the general population to be low. Survival from exercise-related SCA is also indicated to be low, although one study reported survival to be higher following exercise-related SCA compared with nonexercise-related SCA.

What does this study add?

- Incidence of exercise-related SCA was similarly low among the general population in London. The finding of increased survival from exercise-related SCA compared with survival from all out-of-hospital cardiac arrests was replicated in our sample. Survival was significantly associated with an initial cardiac rhythm of ventricular fibrillation/ventricular tachycardia and bystander defibrillation.

How might this impact on clinical practice?

- There is potential for survival from exercise-related SCA to be further enhanced by increasing the availability of public defibrillators and by educating those participating in sports or employed at leisure facilities about the importance of early cardiopulmonary resuscitation (CPR) and defibrillation.

previously reported for this uncommon but catastrophic event, ${ }^{1}{ }^{2}$ although one recent study reported a survival rate of $46.2 \% .^{3}$ There is no standard definition of exercise-related SCD/SCA, but the majority of previous studies focus on cases with a presumed cardiac cause where symptom onset is during or within $1 \mathrm{~h}$ of exercise. ${ }^{45}$

Early estimates of the incidence of exercise-related SCD in the general population range from $10 \%$ to $30 \%$ of all SCD. ${ }^{6}$ However, recent studies have yielded much lower estimates. A retrospective Danish study, in which death certificates of individuals aged between 12 and 35 years were reviewed, reported just $3.5 \%$ of SCDs were sports- 
related. ${ }^{7}$ Similarly, a recent Dutch study estimated that $5.7 \%$ of arrests were exercise-related, ${ }^{3}$ while a prospective French study estimated the incidence of exercise-related SCD among the general population (aged $10-75$ years) to be only 4.6 cases per million population per year. ${ }^{2}$

The incidence of exercise-related SCA in the UK, and in London specifically, has not been established, and survival following SCA related to exercise in the UK has not been examined. Moreover, the prevalence of factors related to survival from this type of SCA, such as bystander CPR and use of public defibrillators, has not been investigated in the UK. The present study aimed to enhance knowledge and improve survival from exercise-related SCA by:

1. Establishing the overall incidence of exercise-related SCA in London among cases attended by the London Ambulance Service and examining characteristics of exercise-related SCA within this population.

2. Investigating return of spontaneous circulation (ROSC) and survival to discharge from hospital.

3. Examining factors related to survival, including bystander CPR, availability of a defibrillator at the location of the incident and use of defibrillators by bystanders.

\section{METHODS}

\section{Study setting}

The London Ambulance Service (LAS) National Health Service (NHS) Trust serves the area of Greater London, which spans an area of approximately 620 square miles and is populated by 8.2 million people. Each year, the LAS receives around 1.6 million calls and attends more than 1 million incidents, ${ }^{8}$ approximately 10000 of which are cardiac arrests.

\section{Design}

The study used a retrospective observational design utilising data held on the LAS cardiac arrest registry relating to out-of-hospital cardiac arrests (OHCAs) occurring from April 2010 to March 2012 in order to investigate exercise-related SCA. Patients were included in the analysis if resuscitation was attempted, a cardiac cause was presumed and there was evidence that the SCA occurred in association with exercise. Ethical approval was not required for the use of routinely collected clinical data. Summary data are presented so as not to allow identification of individual cases.

\section{Data collection procedure}

The cardiac arrest registry contains information on patient demographics, patient condition, treatment administered and patient outcome for all OHCAs attended by LAS clinicians. The registry contains a location field in which the location of the arrest is categorised as private (further subcategorised as home, care home) or public (further subcategorised into work, street, general practitioner surgery, other public; other public further divided into a number of categories including public transport, leisure centre/sports facility, shop, airport, parkland/woodland, school/college, place of worship). We used the location field in the registry to identify possible cases of exercise-related SCA by reviewing cases occurring at locations where individuals were most likely to engage in exercise. We reviewed all cases occurring in the street, leisure centres/sports facilities, parkland/woodland, school/colleges and community centres. We excluded cases occurring in private locations as exercise was considered less likely to occur at these locations.

We included cases as exercise-related if the individual was engaged in a sporting or exercise activity of at least moderate intensity, for example, running, swimming, cycling, gym class at the time/within $1 \mathrm{~h}$ of arrest. We did not include exercise/games of low intensity, for example, snooker, darts, recreational walking or physical activities such as carrying boxes. Only cases where resuscitation was attempted and the cause of arrest was presumed to be cardiac were extracted. The free text section of the clinical record completed by the attending ambulance clinician for these cases was examined for evidence that the patient was engaged in exercise at the time of, or prior to, SCA.

The registry provided information relating to (1) demographic and clinical information (age, gender, ethnicity, initial cardiac rhythm), (2) circumstances of the arrest (whether the arrest was witnessed, bystander CPR, defibrillation before LAS arrival), (3) LAS treatment and (4) patient outcome (ROSC, ROSC sustained to hospital, survival to hospital discharge). Information relating to exercise-related circumstances of the arrest (location, type of exercise, whether the SCA occurred during or after exercise) was obtained from the free text section of the clinical record. The LAS database of publicly sited defibrillators was also accessed to determine whether a defibrillator was available at arrest locations at the time of the arrest.

Summary data relating to all patients with OHCA for whom resuscitation was attempted and a cardiac aetiology was presumed attended by the LAS for the same period were also collected. This was to allow for comparison of patient characteristics and survival between patients experiencing exercise-related SCA and the overall cohort of patients with OHCA for whom resuscitation was attempted and a cardiac aetiology was presumed, attended by the LAS during the same period. It was decided to make comparisons with patients for whom resuscitation was attempted and a cardiac aetiology was presumed-as opposed to all patients with OHCAbecause all the exercise-related SCA cases had a presumed cardiac cause and resuscitation attempted. Thus, it did not seem logical to make comparisons with patients with a cardiac arrest resulting from a non-cardiac cause or for whom resuscitation was not attempted. 


\section{Data analysis}

Descriptive statistics were used to describe the characteristics of the exercise-related SCA cases. Associations between arrest characteristics and survival to hospital discharge were examined using Pearson's $\chi^{2}$ or Fisher's exact test. A $p$ value of $<0.05$ was considered significant for a two-sided test. Statistical analyses were performed using SPSS V.19 except where contingency tables were larger then $2 \times 2$, in which case the Fisher's exact probability test at VassarStats was used (http:// vassarstats.net).

To allow comparison of survival with previously published LAS cardiac arrest figures and other previous studies, an Utstein comparator definition was used. ${ }^{9}$ The definition includes cardiac arrests where resuscitation is attempted and cardiac aetiology is presumed, are bystander witnessed, and where the presenting cardiac rhythm is ventricular fibrillation (VF) or ventricular tachycardia (VT). Inclusion of cases according to the Utstein reporting template is presented in figure 1 .

\section{RESULTS}

\section{Incidence and characteristics of exercise-related SCA in London}

Incidence

From 1 April 2010 to 31 March 2012, 19605 patients with cardiac arrest were attended by the LAS. Resuscitation was attempted for 9901 patients, 6713 of whom had a presumed cardiac aetiology. Of these 6713 arrests, 1255 occurred in locations where exercise is likely to take place. After examining the ambulance service clinical records for these patients, 100 cases of exercise-related SCA were identified.

This equates to an incidence of $8 \%$ of the 1255 clinical records reviewed, $0.5 \%$ of all cardiac arrests attended by the LAS, $1 \%$ of all cardiac arrests attended where resuscitation was attempted, and $1.5 \%$ of all cases where resuscitation was attempted and cardiac aetiology was presumed. The incidence of exerciserelated SCA in the general population of London among cases attended by the LAS was 0.6 per 100000 person-years.

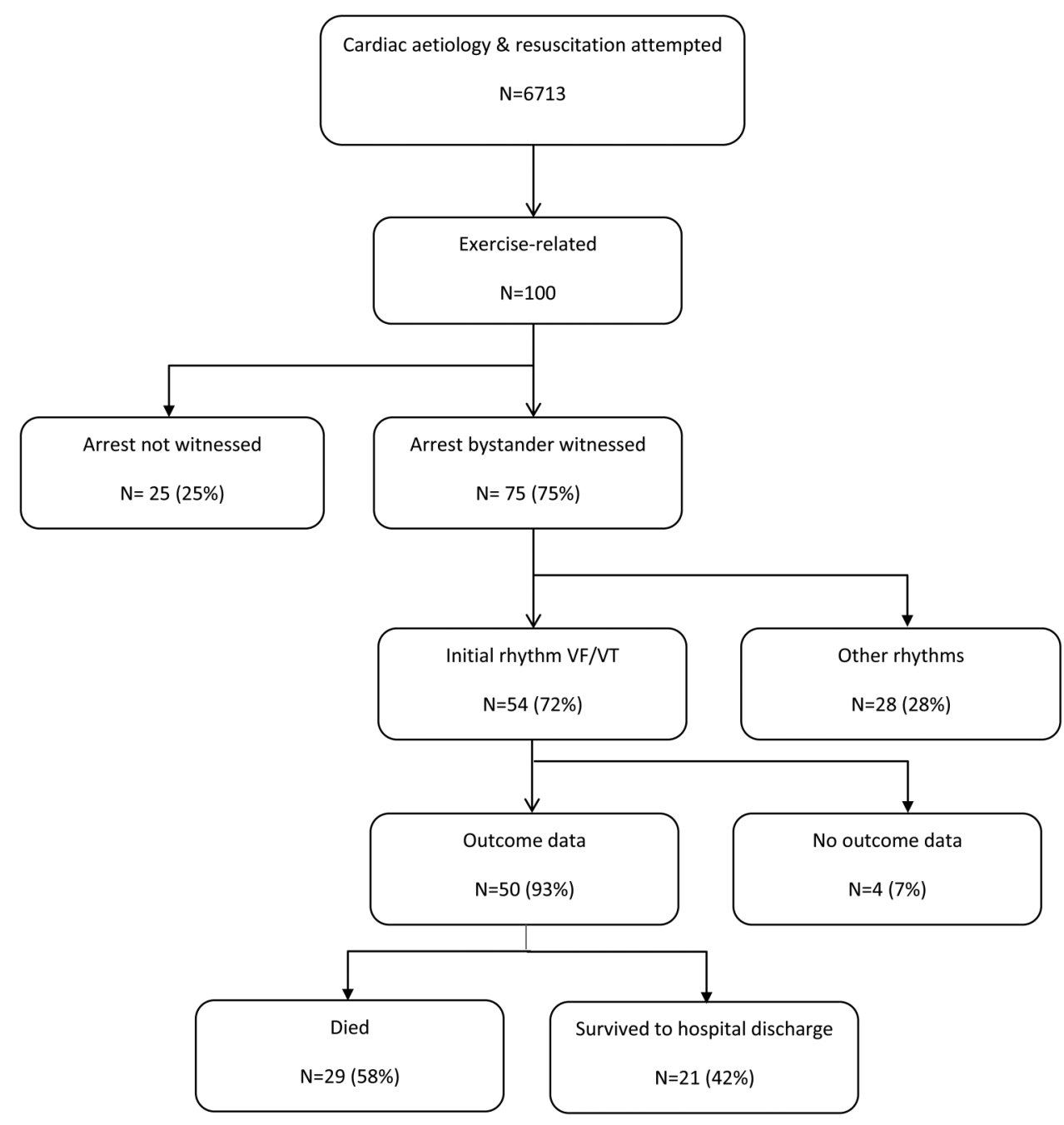

Figure 1 Utstein reporting template (VF/NT, ventricular fibrillation/ventricular tachycardia). 
Table 1 Patient and arrest characteristics

\begin{tabular}{|c|c|c|c|c|c|}
\hline & \multicolumn{2}{|c|}{ Exercise SCA } & \multicolumn{2}{|c|}{ Presumed cardiac OHCA* } & \\
\hline & $\mathbf{N}$ & Per cent & $\mathbf{N}$ & Per cent & \\
\hline Age (mean with range in parentheses) & $49.7(9-84)$ & & $68.0(1-108)$ & & $t(105.1)=9.61, p<0.001$ \\
\hline Initial rhythm & & & & & $\chi^{2}=89.57, \mathrm{df}=3, p<0.001$ \\
\hline VF/VT & 68 & 68 & 1745 & 26 & \\
\hline Asystole & 23 & 23 & 3156 & 47 & \\
\hline PEA & 9 & 9 & 1739 & 26 & \\
\hline Unknown & 0 & 0 & 73 & 1 & \\
\hline
\end{tabular}

\section{Characteristics of exercise}

The majority $(66 \%)$ of arrests occurred during exercise, $25 \%$ occurred after exercise and for $9 \%$ it was unclear whether the arrest occurred during or after exercise. The most common location of arrests was sports ground or club $(26 \%)$, followed by gym or leisure centre $(24 \%)$, street $(22 \%)$, and park or recreation ground $(17 \%)$.

\section{Patient characteristics}

The demographic characteristics of patients are reported in table 1 (with overall OHCA data provided for comparison). The majority of patients were male. The mean age of patients was 49.7 years (range $=9-84$ ). Incidence of exercise-related SCA was highest for those aged 5059 years $(21 \%)$ followed by those aged $60-69(15 \%)$ and $40-49$ years (13\%; figure 2$)$. The majority $(60 \%)$ of patients were Caucasian. Just over two-thirds $(68 \%)$ presented with VF/VT as the initial cardiac rhythm. Compared with all presumed cardiac patients with OHCA with resuscitation attempted, patients with exercise-related SCA were more likely to be male $(98 \%$ vs $64 \%, \chi^{2}=48.29, \mathrm{df}=1, \mathrm{p}<0.001$ ), to be younger ( 50 vs 68 years, $\mathrm{t}(105.1)=9.61, \mathrm{p}<0.001)$ and to present with $\mathrm{VF} / \mathrm{VT}\left(68 \%\right.$ vs $\left.26 \%, \chi^{2}=89.57, \mathrm{df}=3, \mathrm{p}<0.001\right)$.

\section{Survival following exercise-related SCA}

ROSC at any time before handover to hospital was obtained by $41 \%$ of patients, while $40.4 \%$ of all patients had ROSC sustained to hospital. Survival to hospital discharge data was available for $95 \%$ of the sample. Thirty patients $(31.6 \%)$ survived to hospital discharge. The Utstein survival rate was $42 \%$. Compared with all presumed cardiac patients with OHCA with resuscitation attempted, patients with exercise-related SCA were more likely to have ROSC sustained to hospital ( $41 \%$ vs $28 \%$, $\left.\chi^{2}=6.42, \mathrm{df}=1, \mathrm{p}<0.05\right)$ and survive to hospital discharge $\left(32 \%\right.$ vs $10 \%, \chi^{2}=49.54, \mathrm{df}=1, \mathrm{p}<0.001$; table 2$)$.

\section{Bystander response}

The majority $(86 \%)$ of exercise-related arrests were witnessed, with $75 \%$ of all exercise-related arrests witnessed by a bystander. Bystander CPR was initiated in $62 \%$ of exercise-related arrests. A public defibrillator was available in $7 \%$ of incidents, but a defibrillator was deployed only in $4 \%$ of arrests. Defibrillation prior to the arrival of the LAS was documented in a further $3 \%$ of arrests (by other emergency medical services or healthcare professionals). Compared with all presumed cardiac patients with OHCA with resuscitation attempted, patients with
Figure 2 Age distribution of patients with exercise-related sudden cardiac arrest.

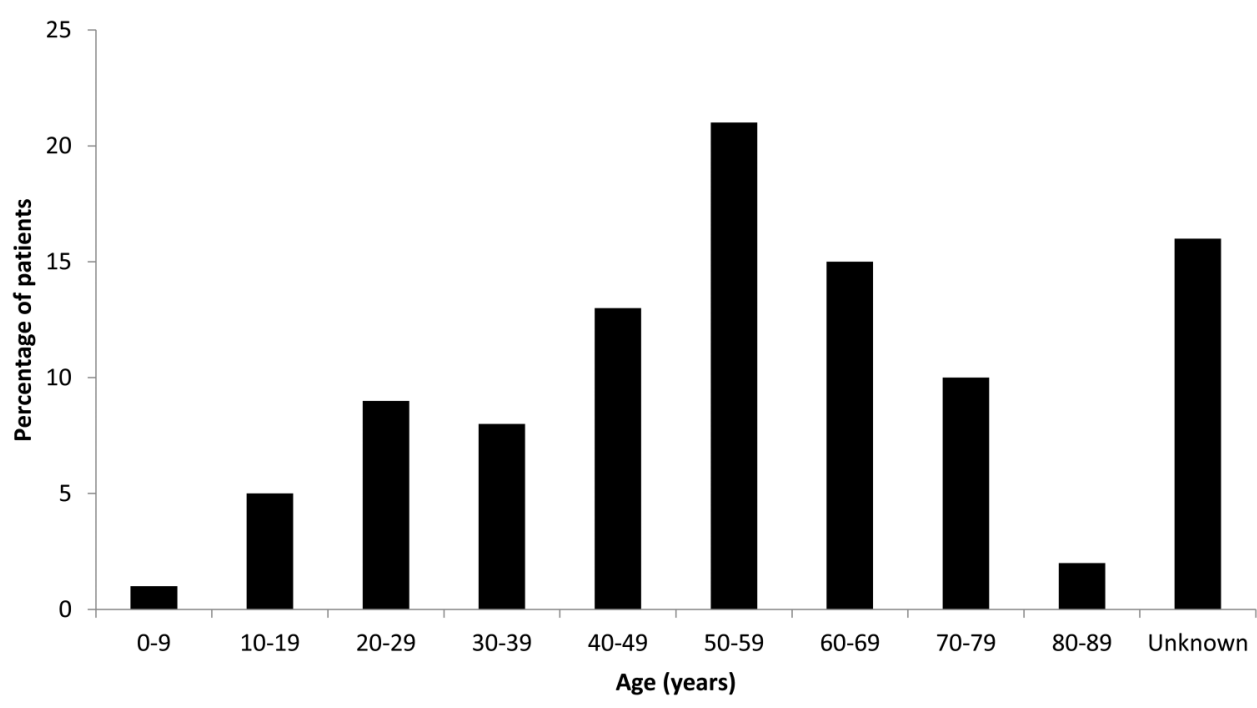


Table 2 Survival to discharge following exercise-related SCA

Exercise SCA

\section{Presumed cardiac OHCA*}

\begin{tabular}{|c|c|c|c|}
\hline \multicolumn{4}{|c|}{ All cases where resuscitation was attempted and a cardiac cause presumed } \\
\hline $\mathrm{N}$ & 100 & 6713 & \multirow{4}{*}{$\begin{array}{l}\chi^{2}=6.42, \mathrm{df}=1, \mathrm{p}<0.05 \\
\chi^{2}=49.54, \mathrm{df}=1, \mathrm{p}<0.001\end{array}$} \\
\hline ROSC before hospital† & $41 \%$ & - & \\
\hline ROSC sustained to hospital & $41 \%$ & $28 \%$ & \\
\hline Survival to discharge $\ddagger$ & $32 \%(30 / 95)$ & $10 \%(621 / 6570)$ & \\
\hline \multicolumn{4}{|l|}{ Utstein§ } \\
\hline $\mathrm{N}$ & 54 & 1079 & \\
\hline Survival $\ddagger$ & $42 \%(21 / 50)$ & $28 \%(281 / 1022)$ & \\
\hline \multicolumn{4}{|c|}{$\begin{array}{l}\text { *Cases where resuscitation was attempted. } \\
\text { †ROSC before hospital was not available for the OHCA sample in 2011-2012. } \\
\text { fCases with missing outcome data are excluded from the denominator. } \\
\text { §Cases where resuscitation was attempted, cardiac aetiology was presumed, bystander witnessed and initial rhythm of VF/VT. } \\
\text { OHCA, out-of-hospital cardiac arrest; ROSC, return of spontaneous circulation; SCA, sudden cardiac arrest. }\end{array}$} \\
\hline
\end{tabular}

exercise-related SCA were more likely to be witnessed by a bystander $\left(75 \%\right.$ vs $\left.46 \%, \chi^{2}=32.86, \quad \mathrm{df}=1, \mathrm{p}<0.001\right)$, receive bystander CPR $\left(62 \%\right.$ vs $39 \%, \chi^{2}=21.69, \mathrm{df}=1$, $\mathrm{p}<0.001)$ and receive bystander defibrillation $(4 \%$ vs $1 \%$, $\chi^{2}=13.32, \mathrm{df}=1, \mathrm{p}<0.001$; table 3 ).

\section{Factors related to survival from exercise-related SCA}

Associations between patient characteristics and survival

Survival was highest for those aged $40-49$ years (54.5\%), followed by those aged $50-59(38.1 \%)$ and $30-39$ years $(37.5 \%)$ although the association between age and survival was not significant (table 4). With regard to gender, there were few females in the sample and survival data were available only for one case; thus, it was not possible to examine gender differences in survival. Similarly, it was not possible to examine ethnicity differences in survival due to the small number of patients from ethnic minorities. A significant association was found between initial rhythm and survival, with the highest survival observed for those presenting with $\mathrm{VF}$ / VT $\left(45 \% ; \chi^{2}=17.49, \mathrm{df}=2, \mathrm{p}<0.001\right)$.

\section{Association between bystander response and survival}

There was a non-significant trend $(p<0.1)$ for an association between bystander CPR and survival, with survival almost double for those who received bystander CPR compared with those who did not (39\% vs $21 \%)$. While a significant association was found between defibrillation prior to LAS arrival and survival (survival: $83 \%$ vs $28 \%$,
Fisher's exact test: $\mathrm{p}<0.05$ ), this finding was based on only six patients receiving defibrillation.

\section{Association between LAS treatment and survival}

As expected, there was a significant association between defibrillation by the LAS and survival, with survival over four times higher for those receiving defibrillation than for those who did not $\left(39 \%\right.$ vs $8 \%, \chi^{2}=4.85, \mathrm{df}=1$, $\mathrm{p}<0.05)$. There was a significant association between advanced airway management and survival, with survival lower for those receiving advanced airway management compared with those who did not $(18 \%$ vs $82 \%$, $\left.\chi^{2}=24.03, \mathrm{df}=1, \mathrm{p}<0.001\right)$.

\section{DISCUSSION}

This study estimated the incidence of exercise-related SCA in the general population in London (among cases attended by the LAS) to be 0.6 per 100000 person-years. It is estimated that 2.5 million people aged over 16 years in London (38\% of its population) participate in weekly exercise of moderate intensity ${ }^{10}$ thus, exercise-related SCA is relatively uncommon. Increased survival from exercise-related SCA was observed compared with survival among all OHCA. Survival was significantly associated with an initial cardiac rhythm of VF/VT and bystander defibrillation.

The incidence reported is comparable to a recent French study, ${ }^{2}$ but it was lower than that reported by studies from Denmark and Holland. ${ }^{3} 7$ This may be due

\section{Table 3 Bystander response}

\begin{tabular}{|c|c|c|c|c|c|}
\hline & \multicolumn{2}{|c|}{ Exercise SCA } & \multicolumn{2}{|c|}{$\begin{array}{l}\text { Presumed cardiac } \\
\text { OHCA }^{*}\end{array}$} & \\
\hline & $\mathbf{N}$ & Per cent & $\mathbf{N}$ & Per cent & \\
\hline Bystander witnessed & 75 & 75 & 3068 & 46 & $\chi^{2}=32.86, \mathrm{df}=1, \mathrm{p}<0.001$ \\
\hline Bystander CPR & 62 & 62 & 2592 & 39 & $\chi^{2}=21.69, \mathrm{df}=1, p<0.001$ \\
\hline Bystander defibrillation & 4 & 4 & 39 & 1 & $\chi^{2}=13.32, \mathrm{df}=1, p<0.001$ \\
\hline
\end{tabular}

${ }^{*}$ Cases where resuscitation was attempted and a cardiac cause presumed.

OHCA, out-of-hospital cardiac arrest; SCA, sudden cardiac arrest. 
Table 4 Survival by patient characteristics, bystander response, and LAS treatment for exercise SCA

\begin{tabular}{|c|c|c|c|c|c|}
\hline \multirow[b]{2}{*}{ Variable } & \multicolumn{2}{|c|}{ Died } & \multicolumn{2}{|c|}{ Survived } & \\
\hline & $\overline{\mathbf{N}}$ & Per cent & $\mathbf{N}$ & Per cent & \\
\hline Age & - & - & - & - & $\chi^{2}=5.91, d f=7, p=N S$ \\
\hline Initial rhythm & & & & & $\chi^{2}=17.49, d f=2, p<0.001$ \\
\hline VF/VT & 35 & 55 & 29 & 45 & \\
\hline Asystole & 22 & 100 & 0 & 0 & \\
\hline PEA & 8 & 89 & 1 & 11 & \\
\hline Bystander CPR & & & & & $\chi^{2}=3.25, d f=1, p<0.1$ \\
\hline Yes & 35 & 61 & 22 & 39 & \\
\hline No & 30 & 79 & 8 & 21 & \\
\hline Pre-LAS defibrillation & & & & & Fisher's exact test: $p<0.05$ \\
\hline Yes & 1 & 17 & 5 & 83 & \\
\hline No & 64 & 72 & 25 & 28 & \\
\hline LAS defibrillation & & & & & $\chi^{2}=4.85, d f=1, p<0.05$ \\
\hline Yes & 43 & 61 & 27 & 39 & \\
\hline No & 22 & 92 & 3 & 8 & \\
\hline Advanced airway management* & & & & & $\chi^{2}=24.03, d f=1, p<0.001$ \\
\hline Yes & 62 & 82 & 14 & 18 & \\
\hline No & 3 & 18 & 14 & 82 & \\
\hline
\end{tabular}

to differences in methodology, for example, the Danish study identified cases of exercise-related SCA from death certificates, while the Dutch study utilised a prospective design. Additionally, differences in denominator between the present study and French study, and the Danish and Dutch studies, may further explain differences in incidence. For example, the present and French studies drew on large populations of over 8 million and almost 34 million, respectively, while the Danish study was restricted to cases aged 12-35 years from an estimated athletic population of 1.6 million and the Dutch study included cases aged 10-90 years from a similarly small population of just over 2 million. The definition of exercise which we adopted is comparable to the definition used by Berdowski et al, ${ }^{3}$ who defined exercise as "being physically active during or within $1 \mathrm{~h}$ before the arrest in a sport discipline, e.g. bicycling, swimming, tennis, running, and fitness workouts at the gym. Manual labour was not considered exercise." Our definition of exercise is also comparable to that used by Sport England. ${ }^{11}$

The mean age of patients and the increase in incidence from age 40 is consistent with previous literature. $^{2} 12$ This is likely to be linked to age-related increases in atherosclerotic coronary artery disease. ${ }^{4} 13$ The majority of cases were male, in line with other studies of exercise-related SCA and SCD in both the general population and athletes. ${ }^{2} 31214$ This may be due to greater participation in exercise by adult men (especially in football-a common activity in the present study) and greater intensity of training, in combination with gender-related differences in the prevalence of underlying causes and later onset of coronary heart disease in women. ${ }^{13} 15$ Two-thirds of exercise-related SCA occurred during exercise, consistent with the findings of de Noronha et $a l^{14}$ who reported that $66 \%$ of exercise-related SCDs occurred during exercise although lower than the $92 \%$ reported by Marijon et al. ${ }^{2}$

Just under one-third of cases survived to hospital discharge, which is lower than the $46.2 \%$ reported in a Dutch study but considerably higher than the 30-day survival rate of $5.5 \%$ reported by a Singaporean study. ${ }^{3} 12$ Survival following exercise-related SCA was higher than that observed in the overall OHCA data for patients with cardiac aetiology and resuscitation attempted for the same period, consistent with the findings of Berdowski et $a l^{3}$ who reported survival from exercise-related SCA to be three times higher than from non-exercise-related SCA. In both the present study and the Berdowski $e t a l^{3}$ study, patients with exercise-related SCA were younger, more likely to be male, and more likely to be witnessed by a bystander and receive bystander CPR compared with non-exercise-related SCA of presumed cardiac aetiology and resuscitation attempted. The higher percentage of patients with VF/VT as the initial rhythm, younger age and increased likelihood of early CPR by a bystander are likely to contribute to the increased survival observed for patients whose arrest was exercise-related. However, Berdowski $e t a \hat{l}$ reported the association between exercise-related SCA and survival remained significant even after controlling for age, gender, initial rhythm and bystander response. They suggested that the improved survival was due to the cardioprotective effect of participating in regular exercise. ${ }^{3}$ 
Three-quarters of exercise-related SCA in the study were witnessed by a bystander, but bystander CPR was initiated in only $62 \%$ of cases. This is comparable to the findings from previous studies of exercise-related SCA/ SCD where very high levels of bystander witnessed arrests were reported, but bystander CPR was lower. ${ }^{2}{ }^{12}$ However, the incidence of bystander CPR in the present study is higher than the overall OHCA data, most likely due to more exercise-related SCA being witnessed. Survival from exercise-related SCA was almost double in cases where bystander CPR was initiated. Although this trend did not reach significance, it highlights the importance of bystander CPR. Public education is needed to inform those participating in exercise or working at locations where exercise is likely to occur of the benefits of early CPR and provide the skills and confidence required to provide effective CPR. The finding that there were cases where defibrillators were available but not used is consistent with those of Deakin et $a l^{16}$ and highlights the importance of providing education and support for staff at locations of public defibrillators to ensure that they have the skills and confidence needed to use the defibrillator when required. Increasing the number of publicly sited defibrillators at locations where exercise is likely to take place-and providing the education and support required to encourage defibrillation-may have the potential to improve survival from exercise-related SCA. ${ }^{17}$

The finding that patients not receiving advanced airway management were more likely to survive is consistent with previous studies of OHCA. ${ }^{18-21}$ This may be due to these patients having received CPR or defibrillation earlier and not requiring advanced airway management or may reflect that those who did require it were more severely ill and/or had more complexity aetiology. ${ }^{1920}$

The present study does have a number of limitations. The overall number of exercise-related deaths was small. There may be some cases of exercise-related SCA that we missed where either the patient was not known to have been engaged in exercise or where this was known but not recorded by ambulance clinicians. Additionally, as we reviewed only cases occurring in locations where exercise was likely to occur, we may have missed cases of exercise-related SCA where the patient was exercising, for example, at home. Thus, it is likely that the incidence of exercise-related SCA in London is underestimated in the present study. Additionally, cases occurring in locations such as leisure centres are more likely to be witnessed and thus recorded compared with cases occurring in parks or in the street. Individuals exercising at leisure centres are likely to be younger and fitter than the overall sample of patients with OHCA. Thus, subsequent analyses may be biased by both the underestimate of incidence and the likely over-representation of cases occurring in locations such as leisure centres.

It was not feasible to identify cases of exercise-related SCA by using a method such as examining death certificates given the large number of deaths that occur in London each year; 47898 deaths were recorded in 2012. ${ }^{22}$ Even if we limited the review of death certificates to those individuals with OHCA attended by the LAS for whom resuscitation was attempted and a cardiac cause presumed, this would have required checking 6713 records, which we did not have the resources for. While it may have been practicable to use death certificates to confirm the cases of exercise-related SCA identified by our study, this would have required the collection of identifiable data such as patient name, date of birth, NHS number, etc, which we did not extract from the clinical records. However, it is generally acknowledged that the extremely low prevalence of exercise-related SCA/SCD limits the accuracy of the estimation of its incidence. ${ }^{15} 23$

It is possible that cases occurring at leisure facilities and sports grounds were spectators rather than participants. However, we consider this to be unlikely since for the majority of cases the clinical record contained enough information to establish the timing of arrest relative to exercise. Finally, we did not collect in-hospital data, thus were unable to account for the potential confounder of in-hospital interventions in the analyses of associations with survival.

In summary, SCA occurring during or shortly after exercise is uncommon among cases attended by the LAS in London, and survival is higher than reported in overall OHCA data for patients with a cardiac aetiology and resuscitation attempted during the same period.

Acknowledgements The authors would like to thank Barry Murphy-Jones and Samantha Taylor for their assistance with data collection for the study. They are also grateful to Lynne Watson for her advice on data collection, to Professor Douglas Chamberlain for his comments on a previous version of the manuscript, and to Malcolm Ritchie for his assistance with accessing the public defibrillator database.

Contributors MJE conceived the study, collated and analysed the data, and drafted the manuscript. RTF revised the manuscript critically for important intellectual content. All authors approved the final manuscript to be published.

Competing interests None declared.

Provenance and peer review Not commissioned; externally peer reviewed.

Open Access This is an Open Access article distributed in accordance with the Creative Commons Attribution Non Commercial (CC BY-NC 4.0) license, which permits others to distribute, remix, adapt, build upon this work noncommercially, and license their derivative works on different terms, provided the original work is properly cited and the use is non-commercial. See: http:// creativecommons.org/licenses/by-nc/4.0/

\section{REFERENCES}

1. Drezner JA, Chun JSDY, Harmon KG, et al. Survival trends in the United States following exercise-related sudden cardiac arrest in the youth: 2000-2006. Heart Rhythm 2008;5:794-9.

2. Marijon E, Tafflet M, Celermajer DS, et al. Sports-related sudden death in the general population. Circulation 2011;124:672-81.

3. Berdowski J, de Beus MF, Blom M, et al. Exercise-related out-of-hospital cardiac arrest in the general population: incidence and prognosis. Eur Heart $J$ 2013;34:3616-23.

4. Futterman LG, Myerburg R. Sudden death in athletes: an update. Sports Med 1998;26:335-50.

5. Rai M, Thompson PD. The definition of exertion-related cardiac events. Br J Sports Med 2011;45:130-1. 
6. Cobb LA, Weaver WD. Exercise: a risk for sudden death in patients with coronary heart disease. J Am Coll Cardiol 1986;7:215-19.

7. Holst AG, Winkel BG, Theilade J, et al. Incidence and etiology of sports-related sudden cardiac death in Denmark-implications for preparticipation screening. Heart Rhythm 2010;7:1365-71.

8. London Ambulance Service. Providing an emergency response. London Ambulance Service, 2013.

9. Cummins RO, Chamberlain DA, Abramson NS, et al. Recommended guidelines for uniform reporting of data from out-of-hospital cardiac arrest: the Utstein Style. A statement for health professionals from a task force of the American Heart Association, the European Resuscitation Council, the Heart and Stroke Foundation of Canada, and the Australian Resuscitation Council. Circulation 1991;84:960-75.

10. Sport England. Active People Survey 8Q3-9Q2. http://www. sportengland.org/research/who-plays-sport/local-picture/ (accessed 15 July 2015)

11. Sport England. ' $1 \times 30$ ' indicator. http://www.sportengland.org/research/ about-our-research/1×30-indicator/ (accessed 15 July 2015).

12. Cheah SO, Ong ME, Chuah MB. An eight year review of exercise-related cardiac arrests. Ann Acad Med Singapore 2010;39:542-6.

13. Corrado D, Migliore F, Basso C, et al. Exercise and the risk of sudden cardiac death. Herz 2006;31:553-8.

14. de Noronha SV, Sharma S, Papadakis M, et al. Aetiology of sudden cardiac death in athletes in the United Kingdom: a pathological study. Heart 2009;95:1409-14.

15. Thompson PD, Franklin BA, Balady GJ, et al., American Heart Association Council on Nutrition, Physical Activity, and Metabolism; American Heart Association Council on Clinical Cardiology; American College of Sports Medicine. Exercise and acute cardiovascular events placing the risks into perspective: a scientific statement from the American Heart Association Council on Nutrition, Physical Activity, and Metabolism and the Council on Clinical Cardiology. Circulation 2007:115:2358-68.

16. Deakin CD, Shewry E, Gray HH. Public access defibrillation remains out of reach for most victims of out-of-hospital sudden cardiac arrest. Heart 2014;100:619-23.

17. Hallstrom A, Ornato JP, Weisfeldt M, et al., Public Access Defibrillation Trial Investigators. Public-access defibrillation and survival after out-of-hospital cardiac arrest. N Engl J Med 2004;351:637-46.

18. Holmberg M, Holmberg S, Herlitz J. Low chance of survival among patients requiring adrenaline (epinephrine) or intubation after out-of-hospital cardiac arrest in Sweden. Resuscitation 2002;54:37-45.

19. Hanif MA, Kaji AH, Niemann JT. Advanced airway management does not improve outcome of out-of-hospital cardiac arrest. Acad Emerg Med 2010;17:926-31.

20. Adams JN, Sirel J, Marsden K, et al. Heartstart Scotland: the use of paramedic skills in our of hospital resuscitation. Heart 1997;78:399-402.

21. McMullan J, Gerecht R, Bonomo J, et al. Airway management and out-of-hospital cardiac arrest outcome in the CARES registry. Resuscitation 2014;85:617-22.

22. Office for National Statistics. Death registration summary tables-England and Wales, 2012. http://www.ons.gov.uk/ons/rel/ vsob1/death-reg-sum-tables/2012/index.htm (accessed 23 Oct 2014)

23. Albert CM, Mittleman MA, Chae CU, et al. Triggering of sudden death from cardiac causes by vigorous exertion. New Engl J Med 2000;343:1355-61. 